\title{
Hypothyroidism in patients with colorectal carcinoma treated with fluoropyrimidines
}

\author{
YUTAKA FUJIWARA $^{1,3}$, NAOKO CHAYAHARA ${ }^{1}$, TORU MUKOHARA ${ }^{1,2}$, NAOMI KIYOTA $^{1}$, \\ HIDEO TOMIOKA $^{1}$, YOHEI FUNAKOSHI ${ }^{1}$ and HIRONOBU MINAMI ${ }^{1,2}$ \\ ${ }^{1}$ Division of Medical Oncology/Hematology, Department of Medicine and ${ }^{2}$ Cancer Center, Kobe University Hospital \\ and Graduate School of Medicine, Kobe 650-0017; ${ }^{3}$ Division of Internal Medicine and Thoracic Oncology, \\ National Cancer Center Hospital, Tokyo 104-0045, Japan
}

Received May 13, 2013; Accepted June 10, 2013

DOI: $10.3892 /$ or.2013.2644

\begin{abstract}
Targeted therapy with tyrosine kinase inhibitors, including vascular endothelial growth factor receptors, has been demonstrated to induce hypothyroidism and thyroid dysfunction. Cancer patients with thyroid dysfunction may be underdiagnosed and undertreated. Thyroid function in colorectal cancer patients receiving fluoropyrimidine-based chemotherapy with or without bevacizumab was evaluated at baseline and monthly. In the present study, 3 of $27(11.1 \%)$ patients who received fluoropyrimidine-based chemotherapy developed a thyroid-stimulating hormone (TSH) level $>10 \mu \mathrm{U} / \mathrm{ml}$, and $13(48.1 \%)$ developed an elevation above the upper limit of the normal range. No difference in TSH elevation was noted between the bevacizumab and chemotherapy-alone group (50 vs. $45 \% ; \mathrm{P}=1.00$, respectively). Three $(11.1 \%)$ patients developed a TSH level $>10 \mu \mathrm{U} / \mathrm{ml}$ and 2 with hypothyroidism were treated with thyroid hormone replacement therapy. We demonstrated that bevacizumab does not affect thyroid function but fluoropyrimidines may induce thyroid dysfunction in patients with colorectal cancer. Further investigation is required to clarify the mechanism of fluoropyrimidine-induced thyroid dysfunction.
\end{abstract}

\section{Introduction}

Hypothyroidism has been considered an uncommon adverse effect of cytotoxic anticancer treatment. Recently, however, some small-molecule tyrosine kinase inhibitors (TKIs) have been demonstrated to induce hypothyroidism and thyroid function test abnormalities (1,2). The oral multitarget inhibitor sunitinib, for example, has been associated with hypothyroidism in $36-85 \%$ of patients, ranging from transient increases

Correspondence to: Dr Yutaka Fujiwara, Division of Internal Medicine and Thoracic Oncology, National Cancer Center Hospital, Tsukiji 5-1-1, Chuo-ku, Tokyo 104-0045, Japan

E-mail: yutakafu@ncc.go.jp

Key words: hypothyroidism, fluoropyrimidines, 5-fluorouracil, bevacizumab, colorectal cancer in thyroid-stimulating hormone (TSH) to persistent hypothyroidism requiring thyroxine replacement therapy (2-5). Sunitinib also induces thyrotoxicosis due to destructive thyroiditis (6). Sorafenib is reported to be responsible for hypothyroidism in $18 \%$ of patients with metastatic renal-cell carcinoma $(7,8)$, while imatinib worsens preexisting hypothyroidism or causes de novo hypothyroidism $(9,10)$. A cohort study conducted in Germany reported incidence rates of sunitinib- and sorafenibinduced hypothyroidism of 24.2 and 12.1 per 100 person-years, respectively (1). However, the effects of other molecular target agents on thyroid function are unknown.

Common symptoms of thyroid hormone deficiency include fatigue, cold intolerance, weight gain, constipation, myalgia and menstrual irregularities. Because these typical clinical manifestations lack specificity, however, the diagnosis of hypothyroidism generally relies on laboratory tests. The United States National Health and Nutrition Examination Survey reports that the prevalence of hypothyroidism is $4.6 \%$, of which $0.3 \%$ is clinical and $4.3 \%$ is subclinical (11). Cancer-related fatigue is common in patients receiving cytotoxic chemotherapy for cancer, and prevalence exceeds $75 \%$ in patients with metastatic disease, suggesting that thyroid dysfunction may be underdiagnosed and undertreated in cancer patients. The management of thyroid dysfunction and possible related symptoms, such as fatigue, represents a challenge to oncologists (12).

Several mechanisms of the pathogenesis of TKI-induced hypothyroidism have been considered. The most plausible are destructive thyroiditis, an immune-mediated thyroiditis in which the synthesis of thyroid hormones related to inhibition of thyroid peroxidase activity is decreased; and drug-induced regression of the gland vascular bed with significant capillary alteration and reduction in density via the inhibition of vascular endothelial growth factor (VEGF) signaling (2,5,7,13-15). Regarding thyroid autoantibodies, the presence of thyroglobulin antibodies was not associated with either the incidence or severity of thyroid dysfunction (4). Although it has been suggested that VEGFR inhibitors decrease thyroid function by interfering with VEGF function or impairing thyroid blood flow, the role of VEGF in thyroid signaling is unknown (16).

Bevacizumab, a monoclonal antibody for VEGF-A which thus differs from anti-angiogenic TKIs, is now approved for the 
treatment of colorectal cancer, non-squamous non-small cell lung cancer, and breast cancer, in combination with chemotherapy (17-19). Although bevacizumab's anti-angiogenic effect might also induce thyroid dysfunction, the effect of bevacizumab on thyroid function has not been investigated (20). Here, we evaluated thyroid function in patients receiving bevacizumab in combination with fluoropyrimidine-based chemotherapy and the effect of a VEGF monoclonal antibody on thyroid function.

\section{Materials and methods}

Patients and evaluation of thyroid function. The study was conducted under an observational design in patients with colorectal cancer who received fluoropyrimidine-based chemotherapy at Kobe University Hospital. Eligibility criteria were age $\geq 18$ years, histologically confirmed adenocarcinoma of the colorectum, Eastern Cooperative Oncology Group performance status of 0 to 2 , and no previous systemic chemotherapy except adjuvant therapy. A history of fluoropyrimidine-based adjuvant chemotherapy was allowed if disease recurrence occurred within 6 months after completion. Patients with a history of hypothyroidism, hyperthyroidism, or thyroid hormone replacement therapy were excluded. Administration of bevacizumab was at the discretion of the attending physician. The study was approved by the institutional review board of Kobe University Hospital.

All patients were evaluated for serum TSH and free thyroxine (fT4) levels at baseline and monthly thereafter. Fatigue, lethargy, intolerance to cold or heat, body weight change, disturbed sweating and menstrual irregularities possibly associated with thyroid dysfunction were recorded by the attending physician. The decision to initiate thyroid replacement therapy was made by the attending physician in accordance with clinical presentation.

Treatment schedule. Patients received fluoropyrimidine-based chemotherapy at the discretion of the attending physician, namely with mFOLFOX6, FOLFIRI, XELOX, or capecitabine monotherapy. mFOLFOX6 consisted of concurrent folic acid $\left(200 \mathrm{mg} / \mathrm{m}^{2}\right)$ and oxaliplatin $\left(85 \mathrm{mg} / \mathrm{m}^{2}\right)$ followed by a bolus injection of 5 -fluorouracil (5FU) $\left(400 \mathrm{mg} / \mathrm{m}^{2}\right)$ on day 1 and subsequent continuous infusion of $5 \mathrm{FU}\left(2400 \mathrm{mg} / \mathrm{m}^{2}\right)$ over $46 \mathrm{~h}$, repeated every 2 weeks. XELOX consisted of oxaliplatin $\left(130 \mathrm{mg} / \mathrm{m}^{2}\right)$ on day 1 followed by oral capecitabine $\left(1,000 \mathrm{mg} / \mathrm{m}^{2}\right)$ twice daily on days 1 to 14 , repeated every 3 weeks. To prevent serious peripheral sensory neuropathy, oxaliplatin was administrated using the stop-and-go strategy in patients with metastatic colorectal cancer and omitted in any patient with neuropathy of grade 2 or more. FOLFIRI consisted of concurrent folic acid $\left(200 \mathrm{mg} / \mathrm{m}^{2}\right)$ and irinotecan $\left(150 \mathrm{mg} / \mathrm{m}^{2}\right)$ followed by a bolus injection of $5 \mathrm{FU}$ $\left(400 \mathrm{mg} / \mathrm{m}^{2}\right)$ on day 1 and subsequent continuous infusion of $5 \mathrm{FU}\left(2,400 \mathrm{mg} / \mathrm{m}^{2}\right)$ over $46 \mathrm{~h}$, repeated every 2 weeks. Irinotecan dose in FOLFIRI was $150 \mathrm{mg} / \mathrm{m}^{2}$, the approved dose in Japan. Capecitabine monotherapy consisted of oral capecitabine $\left(1,250 \mathrm{mg} / \mathrm{m}^{2}\right)$ twice daily on days 1 to 14 , repeated every 3 weeks.

Treatment was continued until disease progression, death, completion of adjuvant chemotherapy for 24 weeks, unaccept- able toxicity, or patient refusal, whichever came first. Clinical and laboratory toxicity were graded according to the National Cancer Institute Common Terminology Criteria for Adverse Events v3.0. Grade 3 or 4 toxic effects were managed by dose modification and appropriate supportive care. Tumor response was assessed with the Response Evaluation Criteria in Solid Tumor (RECIST) v1.0 every 8 to 12 weeks, or sooner if disease progression was suspected (21).

Definition of hypothyroidism. The biochemical diagnosis of subclinical and clinical hypothyroidism was determined in accordance with the guidelines of the American Thyroid Association (ATA), the American Association of Clinical Endocrinologists (AACE) and the Endocrine Society. Subclinical hypothyroidism was considered as a serum TSH level above the upper limit of normal, with fT4 within normal limits. Clinical hypothyroidism was defined as low serum fT4 together with elevated TSH. Patients with at least two consecutive TSH measurements $>10 \mu \mathrm{U} / \mathrm{ml}$ and those with TSH above the upper limit of normal and symptoms compatible with hypothyroidism (e.g., fatigue, cold intolerance, constipation or weight gain) received thyroid hormone replacement therapy with L-thyroxine (22). Normal ranges in our laboratory are $0.45-3.81 \mu \mathrm{U} / \mathrm{ml}$ for TSH and $0.82-1.22 \mathrm{ng} / \mathrm{ml}$ for fT4.

Statistical analysis. TSH andfT4 levels of patients who received fluoropyrimidine-based chemotherapy with or without bevacizumab were compared using the Mann-Whitney U test, and differences in clinicopathological variables were examined using Fisher's exact test. All analyses were performed using the SPSS statistical package (SPSS v19.0 for Windows; SPSS, Inc., Chicago, IL, USA).

\section{Results}

Patient demographics. A total of 27 patients with colorectal cancer were enrolled between October 2007 and January 2010. Median follow-up time was 51 weeks (12-192). Patient demographics and baseline characteristics are shown in Table I. Of the total patients, 21 received mFOLFOX6, 3 received FOLFIRI, 2 received XELOX and 1 received capecitabine monotherapy. Sixteen patients $(59.3 \%)$ received bevacizumab in combination with chemotherapy. Combination therapy with bevacizumab was not carried out due to adjuvant chemotherapy in 4 patients, presence of hemorrhagic lesions in 3, use of anticoagulants in 2 and advanced age and Parkinson's disease as a complication in 1 each. The median number of chemotherapy cycles in all patients was 12 (range, 2-35), with 12 (2-35) cycles in the bevacizumab group and 10 (5-27) in the chemotherapy-alone group. Treatment was discontinued due to disease progression in $12(44.4 \%)$ patients and adverse events in $8(29.6 \%)$, while the remaining 7 patients completed adjuvant therapy.

Thyroid function. Thyroid hormone parameters are provided in Table II. No patients had fatigue or other symptoms associated with thyroid dysfunction at baseline. At baseline, the mean TSH level was $1.72 \mu \mathrm{U} / \mathrm{ml}$ in the bevacizumab group and $2.00 \mu \mathrm{U} / \mathrm{ml}$ in the chemotherapy-alone group. Three $(11.1 \%)$ patients who received fluoropyrimidine-based chemotherapy 
Table I. Patient demographics and baseline characteristics.

\begin{tabular}{lccc}
\hline & $\begin{array}{c}\text { Chemotherapy } \\
\text { bevacizumab } \\
\mathrm{n}=16\end{array}$ & $\begin{array}{c}\text { Chemotherapy } \\
\mathrm{n}=11\end{array}$ & P-value \\
& $63(42-77)$ & $71(37-79)$ & 0.24 \\
$\begin{array}{l}\text { Age, years } \\
\text { Median (range) }\end{array}$ & $11 / 5$ & $8 / 3$ & 0.82 \\
$\begin{array}{l}\text { Gender } \\
\text { Male/female }\end{array}$ & $8 / 7 / 1$ & $5 / 3 / 3$ & 0.78 \\
$\begin{array}{l}\text { ECOG PS } \\
\text { 0/1/2 }\end{array}$ & $8 / 8$ & $5 / 6$ & 0.82 \\
$\begin{array}{l}\text { Primary site } \\
\text { Colon/rectum }\end{array}$ & $12(2-35)$ & $10(5-27)$ & 0.74 \\
$\begin{array}{l}\text { Treatment cycles } \\
\text { Median (range) }\end{array}$ & & & \\
$\begin{array}{l}\text { Reason for } \\
\text { discontinuation } \\
\text { Progression } \\
\begin{array}{l}\text { Completion of adjuvant } \\
\text { chemotherapy } \\
\text { Adverse events }\end{array}\end{array}$ & 4 & 5 & \\
\hline
\end{tabular}

ECOG, Eastern Clinical Oncology Group; PS, performance status.

developed a TSH level $>10 \mu \mathrm{U} / \mathrm{ml}$ and 13 (48.1\%) developed an elevation above the upper limit of the normal range. In the limited observational period, a considerable number of patients developed clinical and subclinical hypothyroidism irrespective of bevacizumab use. Eight of 16 patients $(50 \%)$ in the bevacizumab group and 5 of 11 (45\%) in the chemotherapy-alone group experienced elevation of TSH above the upper normal limit $(\mathrm{P}=1.00)$, while $2(12.5 \%)$ in the bevacizumab group and $1(20 \%)$ in the chemotherapy-alone group developed levels $>10 \mu \mathrm{U} / \mathrm{ml}(\mathrm{P}=1.00)$. There were no differences in TSH and
fT4 level between the bevacizumab and chemotherapy-alone groups. One of 3 patients in the bevacizumab group who developed a TSH level $>10 \mu \mathrm{U} / \mathrm{ml}$ showed only a transient increase in TSH $(13.62 \mu \mathrm{U} / \mathrm{ml})$ and decrease in free $\mathrm{T} 4(0.76 \mathrm{ng} / \mathrm{ml})$, and these levels were improved the next month without any treatment. The remaining 2 patients received thyroid hormone replacement therapy with L-thyroxine, as detailed below. In 12 patients with TSH levels above the upper limit of normal, median time to exceeding this level was 18 (4-64) weeks. Median time to highest TSH level was 25 (4-53) weeks.

Case presentation 1 (Fig. 1A). A 71-year-old male was diagnosed with sigmoid colon cancer (T3N1) with solitary liver metastasis. He underwent surgical resection for the primary tumor and liver metastasis, and then received adjuvant chemotherapy with mFOLFOX plus bevacizumab for a total of 12 courses. After 11 courses, he experienced an increase in TSH $(11.48 \mu \mathrm{U} / \mathrm{ml})$ and decrease in fT4 $(0.81 \mathrm{ng} / \mathrm{ml})$, with the increase in $\mathrm{TSH}$ maintained the next month $(10.1 \mu \mathrm{U} / \mathrm{ml})$. He reported grade 1 fatigue, which resolved following thyroid hormone replacement therapy. Two years after completing adjuvant chemotherapy, he is alive without recurrence and is still receiving hormone replacement therapy.

Case presentation 2 (Fig. 1B). A 71-year-old male was diagnosed with colorectal cancer with multiple liver and lymph node metastases. Colonoscopy revealed an easily bleeding ulcerative lesion on the ascending colon. After seven courses of mFOLFOX therapy, the TSH level was $10.06 \mu \mathrm{U} / \mathrm{ml}$ but fT4 level was normal $(1.15 \mathrm{ng} / \mathrm{ml})$. After 10 courses, he had grade 2 fatigue and grade 2 peripheral sensory neuropathy. Because TSH was increased to $14.2 \mu \mathrm{U} / \mathrm{ml}$, he received thyroid hormone replacement therapy and continued chemotherapy but with oxaliplatin omitted. CT at 7 months of treatment showed progression of liver metastases, for which he received second-line chemotherapy with irinotecan, but he died of primary disease at 11 months of treatment.

Table II. Thyroid hormone parameters.

\begin{tabular}{|c|c|c|c|c|c|}
\hline & $\begin{array}{c}\text { Chemotherapy }+ \\
\text { bevacizumab } \\
n=16\end{array}$ & $\begin{array}{c}\text { Chemotherapy } \\
n=11\end{array}$ & P-value & $\begin{array}{l}\text { All patients } \\
n=27\end{array}$ & P-value \\
\hline \multicolumn{6}{|l|}{$\mathrm{TSH}(0.45-3.81 \mu \mathrm{U} / \mathrm{ml})$} \\
\hline At baseline & $1.72 \pm 0.97$ & $2.00 \pm 0.86$ & 0.31 & $1.83 \pm 0.92$ & \\
\hline Two months after treatment & $2.47 \pm 1.55$ & $2.64 \pm 1.91$ & 0.92 & $2.54 \pm 1.68$ & $0.06^{\mathrm{a}}$ \\
\hline $\begin{array}{l}\text { Ratio of TSH at baseline and } \\
2 \text { months after treatment }\end{array}$ & $1.51 \pm 0.64$ & $1.31 \pm 0.52$ & 0.32 & & \\
\hline Maximum TSH & $4.54 \pm 3.56$ & $6.31 \pm 8.42$ & 0.81 & $5.26 \pm 5.95$ & $0.005^{\mathrm{a}}$ \\
\hline \multicolumn{6}{|l|}{ fT4 $(0.82-1.22 \mathrm{ng} / \mathrm{ml})$} \\
\hline At baseline & $1.15 \pm 0.20$ & $1.15 \pm 0.25$ & 0.94 & $1.15 \pm 0.22$ & \\
\hline Two months after treatment & $1.13 \pm 0.15$ & $1.16 \pm 0.22$ & 0.61 & $1.14 \pm 0.18$ & $0.89^{\mathrm{a}}$ \\
\hline Patients with TSH above ULN, n (\%) & $8(50)$ & $5(45)$ & 1.00 & $13(48.1)$ & \\
\hline Patients with TSH > $10 \mu \mathrm{U} / \mathrm{ml}, \mathrm{n}(\%)$ & $2(12.5)$ & $1(9)$ & 1.00 & $3(11.1)$ & \\
\hline
\end{tabular}

${ }^{\mathrm{a} C o m p a r e d ~ w i t h ~ t h e ~ b a s e l i n e ~ l e v e l . ~ D a t a ~ a r e ~ e x p r e s s e d ~ a s ~ t h e ~ m e a n ~} \pm$ SD or no. of patients (\%). TSH, thyroid-stimulating hormone; fT4, free thyroxin; ULN, upper limit of normal. 
A

\section{mFOLFOX6+BV 12 course

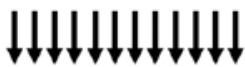

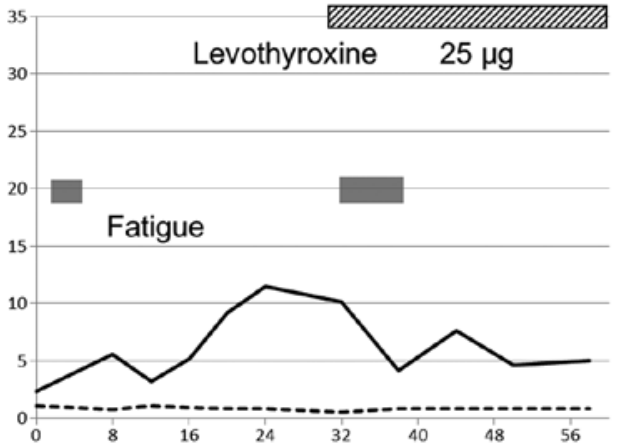

B
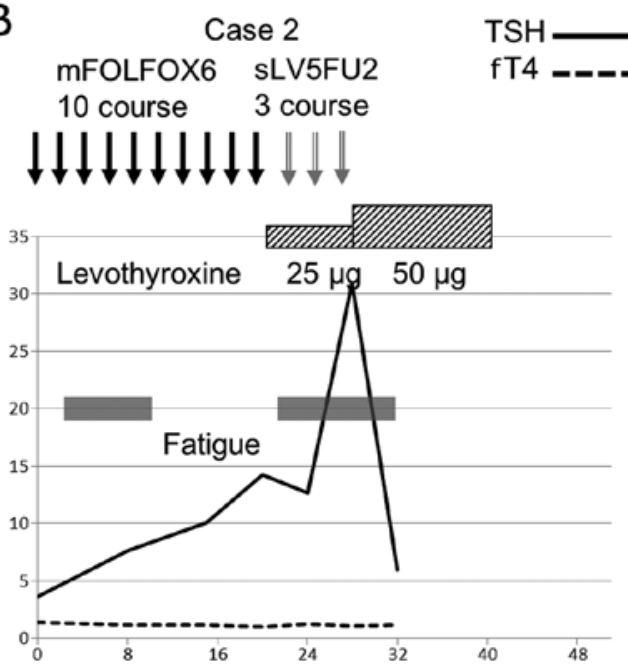

Figure 1. Clinical course of 2 patients [(A) case 1 and (B) case 2] with hypothyroidism. BV, bevacizumab; fT4, free thyroxine; mFOLFOX6, oxaliplatin $85 \mathrm{mg} / \mathrm{m}^{2}$ intravenously on day 1 , leucovorin $400 \mathrm{mg} / \mathrm{m}^{2}$ intravenously on day 1 and fluorouracil $400 \mathrm{mg} / \mathrm{m}^{2}$ intravenously on day 1 , followed by continuous infusion of $2,400 \mathrm{mg} / \mathrm{m}^{2}$ over the next 46 h every 2 weeks; sLV5FU2, leucovorin $400 \mathrm{mg} / \mathrm{m}^{2}$ intravenously on day 1 and fluorouracil $400 \mathrm{mg} / \mathrm{m}^{2}$ intravenously on day 1 , followed by continuous infusion of $2,400 \mathrm{mg} / \mathrm{m}^{2}$ over the next $46 \mathrm{~h}$ every 2 weeks; TSH, thyroid-stimulating hormone.<smiles>O=c1[nH]cc(F)c(=O)[nH]1</smiles><smiles>CCCc1cc(=O)[nH]c(=S)[nH]1</smiles>

Figure 2. Chemical structural formula of (A) 5-fluorouracil and (B) propylthiouracil.

\section{Discussion}

In this observational study in patients with colorectal cancer, we found that bevacizumab seemed to have no effect on thyroid function, whereas fluoropyrimidines did induce thyroid dysfunction. All cases of fluoropyrimidine-induced hypothyroidism appeared to be controllable by thyroid hormone replacement therapy. Further investigation is needed to clarify the mechanism of fluoropyrimidine-induced thyroid dysfunction.

In this analysis, $3(11.1 \%)$ patients who received fluoropyrimidine-based chemotherapy developed TSH levels $>10 \mu \mathrm{U} / \mathrm{ml}$ and $13(49.3 \%)$ showed elevation above the upper limit of the normal range. Considering the median follow-up time of 51 weeks (range, 12-192), this high incidence of thyroid dysfunction is unusual. To our knowledge, an association between colorectal cancer and thyroid dysfunction has not been previously reported. One study reported a significant increase in $\mathrm{T} 4$ and $\mathrm{T} 3$ levels in 15 patients with advanced breast cancer during weekly treatment with 5FU, but no change in fT4 or TSH and no clinical signs of hyperthyroidism (23). However, administration of fluoropyrimidines differed in this previous and our present study.

The mechanism of this putative fluoropyrimidine-induced thyroid dysfunction is currently unclear, as is that of TKI-induced thyroid dysfunction. Although our study did not measure fT3 and rT3, we hypothesize that thyroid dysfunction associated with fluoropyrimidines may be due to altered thyroid hormone metabolism, which also occurs with sorafenib (7). This effect might be related to the structural similarity between 5FU and propylthiouracil (Fig. 2). Capecitabine is also a prodrug that is enzymatically converted to 5FU in tumors. Propylthiouracil, a thioamide drug used to treat hyperthyroidism, inhibits the thyroperoxidase that liberates iodine for addition onto tyrosine residues on thyroglobulin for the production of T4 or T3, as well as thyroid hormones, and also inhibits the enzyme 5'-deiodinase, which converts T4 to the active form T3. Further basic and clinical investigation is required to clarify the mechanism of fluoropyrimidineinduced thyroid dysfunction.

Bevacizumab is classified as a monoclonal antibody and anti-angiogenesis drug which binds to and neutralizes VEGF. In contrast, sunitinib and sorafenib are small-molecule compounds which inhibit cellular signaling by targeting multiple receptor tyrosine kinases, including VEGF receptors. It is suggested that sunitinib and sorafenib decrease thyroid function by interfering with VEGF function or impairing thyroid blood flow $(2,24)$. In several reports, however, including the present analysis, bevacizumab did not appear to be associated with altered thyroid homeostasis $(25,26)$. Based on this finding, the neutralization of VEGF would therefore have no significant effect on thyroid function.

In the present study, 2 patients who experienced hypothyroidism were effectively treated with hormone replacement therapy, as judged from measured TSH levels. Administration of thyroid hormone replacement therapy reversed the fluoropyrimidine-induced severe fatigue in these patients.

In conclusion, bevacizumab did not affect thyroid function in these patients with colorectal cancer, whereas fluoropyrimidines did induce thyroid dysfunction. Thyroid hormone replacement therapy may relieve the symptoms of fluoropyrimidine-induced hypothyroidism. Further investigation is required to clarify the mechanism of fluoropyrimidine-induced thyroid dysfunction. 


\section{Acknowledgements}

The authors are grateful to the physicians, nurses and other medical staff of the Medical Oncology/Hematology unit of Kobe University Hospital and the Graduate School of Medicine for their support.

\section{References}

1. Feldt S, Schüssel K, Quinzler R, et al: Incidence of thyroid hormone therapy in patients treated with sunitinib or sorafenib: a cohort study. Eur J Cancer 48: 974-981, 2012.

2. Torino F, Corsello SM, Longo R, Barnabei A and Gasparini G: Hypothyroidism related to tyrosine kinase inhibitors: an emerging toxic effect of targeted therapy. Nat Rev Clin Oncol 6: 219-228, 2009.

3. Desai J, Yassa L, Marqusee E, et al: Hypothyroidism after sunitinib treatment for patients with gastrointestinal stromal tumors. Ann Intern Med 145: 660-664, 2006.

4. Rini BI, Tamaskar I, Shaheen P, et al: Hypothyroidism in patients with metastatic renal cell carcinoma treated with sunitinib. J Natl Cancer Inst 99: 81-83, 2007.

5. Wong E, Rosen LS, Mulay M, et al: Sunitinib induces hypothyroidism in advanced cancer patients and may inhibit thyroid peroxidase activity. Thyroid 17: 351-355, 2007.

6. Faris JE, Moore AF and Daniels GH: Sunitinib (Sutent)-induced thyrotoxicosis due to destructive thyroiditis: a case report Thyroid 17: 1147-1149, 2007.

7. Abdulrahman RM, Verloop H, Hoftijzer H, et al: Sorafenibinduced hypothyroidism is associated with increased type 3 deiodination. J Clin Endocrinol Metab 95: 3758-3762, 2010.

8. Tamaskar I, Bukowski R, Elson P, et al: Thyroid function test abnormalities in patients with metastatic renal cell carcinoma treated with sorafenib. Ann Oncol 19: 265-268, 2008.

9. de Groot JW, Zonnenberg BA, Plukker JT, van Der Graaf WT and Links TP: Imatinib induces hypothyroidism in patients receiving levothyroxine. Clin Pharmacol Ther 78: 433-438, 2005

10. de Groot JW, Zonnenberg BA, van Ufford-Mannesse PQ, et al: A phase II trial of imatinib therapy for metastatic medullary thyroid carcinoma. J Clin Endocrinol Metab 92: 3466-3469, 2007.

11. Hollowell JG, Staehling NW, Flanders WD, et al: Serum TSH, $\mathrm{T}(4)$, and thyroid antibodies in the United States population (1988 to 1994): National Health and Nutrition Examination Survey (NHANES III). J Clin Endocrinol Metab 87: 489-499, 2002.

12. Eisen T, Sternberg CN, Robert C, et al: Targeted therapies for renal cell carcinoma: review of adverse event management strategies. J Natl Cancer Inst 104: 93-113, 2012.
13. Iavarone $\mathrm{M}$, Perrino $\mathrm{M}$, Viganò $\mathrm{M}$, Beck-Peccoz $\mathrm{P}$ and Fugazzola L: Sorafenib-induced destructive thyroiditis. Thyroid 20: 1043-1044, 2010

14. Kappers MH, van Esch JH, Smedts FM, et al: Sunitinib-induced hypothyroidism is due to induction of type 3 deiodinase activity and thyroidal capillary regression. J Clin Endocrinol Metab 96: 3087-3094, 2011.

15. Shinohara N, Takahashi M, Kamishima T, et al: The incidence and mechanism of sunitinib-induced thyroid atrophy in patients with metastatic renal cell carcinoma. Br J Cancer 104: 241-247, 2011.

16. Kim S, Yazici YD, Calzada G, et al: Sorafenib inhibits the angiogenesis and growth of orthotopic anaplastic thyroid carcinoma xenografts in nude mice. Mol Cancer Ther 6: 1785-1792, 2007.

17. Saltz LB, Clarke S, Díaz-Rubio E, et al: Bevacizumab in combination with oxaliplatin-based chemotherapy as first-line therapy in metastatic colorectal cancer: a randomized phase III study. J Clin Oncol 26: 2013-2019, 2008.

18. Sandler A: Bevacizumab in non-small cell lung cancer. Clin Cancer Res 13: s4613-s4616, 2007.

19. Miller K, Wang M, Gralow J, et al: Paclitaxel plus bevacizumab versus paclitaxel alone for metastatic breast cancer. $\mathrm{N}$ Engl J Med 357: 2666-2676, 2007.

20. Van Meter ME and Kim ES: Bevacizumab: current updates in treatment. Curr Opin Oncol 22: 586-591, 2010

21. Therasse P, Arbuck SG, Eisenhauer EA, et al: New guidelines to evaluate the response to treatment in solid tumors. European Organization for Research and Treatment of Cancer, National Cancer Institute of the United States, National Cancer Institute of Canada. J Natl Cancer Inst 92: 205-216, 2000.

22. Cooper DS: Clinical practice. Subclinical hypothyroidism. N Engl J Med 345: 260-265, 2001.

23. Beex L, Ross A, Smals A and Kloppenborg P: 5-fluorouracilinduced increase of total serum thyroxine and triiodothyronine. Cancer Treat Rep 61: 1291-1295, 1977.

24. Kamba T and McDonald DM: Mechanisms of adverse effects of anti-VEGF therapy for cancer. Br J Cancer 96: 1788-1795, 2007.

25. Wang JF, Milosveski V, Schramek C, Fong GH, Becks GP and Hill DJ: Presence and possible role of vascular endothelial growth factor in thyroid cell growth and function. J Endocrinol 157: 5-12, 1998.

26. Gordon MS, Margolin K, Talpaz M, et al: Phase I safety and pharmacokinetic study of recombinant human anti-vascular endothelial growth factor in patients with advanced cancer. J Clin Oncol 19: 843-850, 2001. 